\title{
Verification of cloud cover forecast with INSAT observation over western India
}

\author{
Shivani Shah, B M RaO*, Prashant Kumar and P K PaL \\ Meteorology $\&$ Oceanography Group, Space Applications Centre (ISRO), Ahmedabad 380 015, India. \\ *e-mail: bmrao100@yahoo.com
}

\begin{abstract}
Since the beginning of the summer monsoon 2009, experimental mesoscale weather forecasts in real time are being generated using WRF model by the Meteorology and Oceanography Group at the Space Applications Centre (ISRO) and are disseminated through MOSDAC (www.mosdac.gov.in) to various users. To begin with, the $12 \mathrm{~h}, 24 \mathrm{~h}$ and $48 \mathrm{~h}$ forecasts for the western India region are made available. A study is undertaken to comprehensively assess the cloudiness prediction performance of WRF model. The evaluations have been made over the three months period during monsoon 2009. INSAT cloud imagery data has been used as a reference for these evaluations. The verification strategy includes computation of various skill scores. It is seen that probability of detection (POD) of cloud is $84 \%$ and the false alarm rate (FAR) is around $18 \%$. It is hoped that this assessment will provide information on the use of these forecasts in various applications.
\end{abstract}

\section{Introduction}

Major advances in numerical weather prediction (NWP) during the last few decades have led to significant progress in predicting synoptic weather disturbances particularly over the mid-latitude regions where the underlying dynamical mechanisms are well understood. The high predictability of the mid-latitude weather disturbances is partly due to the fact that the dynamical evolution of these disturbances, which primarily develop through sheared instability of the large scale circulation, is more predictable as compared to the tropics. However, advancing the NWP forecast skills beyond a couple of days still continues to be a major scientific challenge in the tropics in general and monsoon regions in particular. Here, the large scale circulation is strongly coupled to the evolution of smaller-scale cumulus convective systems. The accurate representation of embedded cloud systems, their interaction with large scale environment and the manner in which they organize into large scale cloud clusters is one of the main problems of the tropics.
Development of appropriate models for the weather phenomena has been the major challenge all these years. The research and development activities related to modeling, assimilation of data and forecast need major thrust for the improvement of mesoscale weather forecasting. Improvements towards accurate weather forecasting would need high density network measurements and sophisticated high resolution models with region specific physics and advanced data assimilation techniques, against the present forecast system that adopt global data, models and physics schemes resulting in uncertain forecasts. In this connection, ISRO has established an advanced observational network (PRWONAM) for the mesoscale atmospheric modeling over SHAR region. Similar to this, an observational network has been planned for the different places of northwest India and their use in real-time weather prediction over this region. To facilitate this, the Weather Research and Forecasting (WRF) model has been acquired and customized with high resolution $(5 \mathrm{~km})$ for the western Indian region.

Keywords. WRF model; INSAT; false alarm; probability of detection; cloud mask; brightness temperature. 
Despite significant developments in the dynamical modeling of the atmospheric processes and computer technology, model output is never a perfect forecast of real atmosphere variables for several reasons. Some of these are; insufficient initial conditions, errors in the parameterization of various sub-grid scale processes, computer round-off errors in the integrations, etc., besides predictability.

The intent of this study is to examine differences between the actual observations (distributions of temperature, rainfall and clouds) and those predicted in WRF model forecast variables. Various studies related to forecast verification are in progress, particularly temperature and rainfall. However, here we report preliminary analysis of the verification of the model generated cloudiness with INSAT brightness temperatures.

At any given time clouds cover between 50 and $60 \%$ of the globe and exert various influences on the earth-atmosphere system. The most important of them are (Otkin and Greenwald 2008):

- the release of latent heat due to the phase changes of water,

- the transport of heat, moisture, momentum over large distances in the vertical through convective clouds, and

- the modification of the radiative fluxes in the atmosphere and at earth's surface.

Considering the importance of influences of clouds in the evolution of atmosphere and the underlying surface, the effects have to be incorporated into the atmospheric models used for the prediction of weather. The coarser horizontal grid of these models makes it impossible to directly simulate cloud processes. However, they are included indirectly through parameterizations which are statistical theories, analogous to thermodynamics. It is difficult to capture the variety and complexity of cloud processes in a single cloud parameterization scheme. These uncertainties could result in ambiguous forecast values of model generated cloudiness. The utility of the WRF model cloud forecast observations is assessed through various skill scores.

The demonstration of the cloud prediction capability in WRF model would help in addressing the issues related to the cloud parameterization schemes employed (Morcrette 1990; Molders et al 1995), as well as other applications like satellite missions requiring cloud free days for the acquisition of remote sensing data. The cost of savings by not operating the sensors during high probable cloudy situations would be considerable.

\section{Data and methodology}

\subsection{WRF model setup}

One of the primary objectives of the WRF developmental effort is to improve the ability to represent and forecast convective systems in the 48-h period. The success of such an effort would require the use of sufficient (model) resolution to represent the convective processes, to accurately represent the mesoscale environment of the convective system, and appropriate forecasting of the timing and location of significant convective triggering.

The mesoscale model used is the Advanced Research Weather Research Forecast (WRF-ARW) model version-3.0 developed primarily at NCAR, USA. The WRF is a limited area, non-hydrostatic primitive equation model with multiple option for various physical parameterization schemes, which include precipitation microphysics, cumulus convection, longwave and shortwave radiations, the surface layer, the land surface, the boundary layer, and eddy diffusion. The different physical and dynamical options used for running the model are given in table 1 . WRF model has a provision to run through without assimilation or with local data assimilation using local observations (radiosonde, AWS, INSAT) and 3-dimensional variational data assimilation.

Table 1. Summary of characteristics of the WRF model.

\begin{tabular}{|c|c|c|}
\hline Sl. no. & $\begin{array}{l}\text { Characteristic } \\
\text { feature }\end{array}$ & WRF \\
\hline 1 & $\begin{array}{l}\text { Nesting option } \\
\text { used }\end{array}$ & Yes (3-domain) \\
\hline 2 & Horizontal grid & Arakawa $\mathrm{C}$ grid \\
\hline 3 & Map projection & Mercator \\
\hline 4 & $\begin{array}{l}\text { Time integration } \\
\text { scheme }\end{array}$ & $\begin{array}{l}\text { Third order Runge-Kutta } \\
\text { (Wicker and Skamarock } \\
\text { 2002) }\end{array}$ \\
\hline 5 & Microphysics & $\begin{array}{l}\text { WSM 6-class graupel scheme } \\
\text { (Lin et al 1983; Dudhia } \\
\text { et al 2008) }\end{array}$ \\
\hline 6 & $\begin{array}{l}\text { Radiation (short } \\
\text { wave) }\end{array}$ & $\begin{array}{l}\text { Dudhia scheme (Hong et al } \\
\text { 2004) }\end{array}$ \\
\hline 7 & $\begin{array}{l}\text { Radiation (long } \\
\text { wave) }\end{array}$ & $\begin{array}{l}\text { RRTM scheme (Mlawer et al } \\
\text { 1997) }\end{array}$ \\
\hline 8 & LSM & $\begin{array}{l}\text { Unified Noah Land Surface } \\
\text { Model (Chen and Dudhia } \\
\text { 2001) }\end{array}$ \\
\hline 9 & $\begin{array}{l}\text { Bl PBL Physics } \\
\text { scheme }\end{array}$ & USU (Hong et al 2006) \\
\hline 10 & $\begin{array}{l}\text { Cumulus } \\
\text { parameterization } \\
\text { scheme }\end{array}$ & $\begin{array}{l}\text { Kain Fritsch scheme (Kain } \\
\text { and Fritsch 1990, } 1993 \\
\text { and Kain 2004) }\end{array}$ \\
\hline 11 & Dynamics & $\begin{array}{l}\text { Nonhydrostatic with 3D } \\
\text { Coriolis force }\end{array}$ \\
\hline
\end{tabular}


The WRF model described in table 1 is integrated for 48 hours in a triple domain configuration with a horizontal resolution of $45 \mathrm{~km}$, $15 \mathrm{~km}$ and $5 \mathrm{~km}$ for the western India with grid points $110 \times 110,121 \times 121$ and $217 \times 217$ in $x$ and $y$ directions for the domains 1,2 and 3, respectively. The domain details of the model configured for three domains are given below:

Domain 1: Lat. $\left(2^{\circ}-42^{\circ} \mathrm{N}\right)$, Long. $\left(50^{\circ}-94^{\circ} \mathrm{E}\right)$

Domain 2: Lat. $\left(14^{\circ}-29^{\circ} \mathrm{N}\right)$, Long. $\left(62^{\circ}-78^{\circ} \mathrm{E}\right)$

Domain 3: Lat. $\left(17^{\circ}-26^{\circ} \mathrm{N}\right)$, Long. $\left(65.5^{\circ}-75.5^{\circ} \mathrm{E}\right)$

During the installation and customization of the WRF model, a number of experiments were designed to configure the model for appropriate parameterization (convection, radiation), microphysics, etc., and to simulate special weather events. Heavy rainfall over Mumbai (July 26, 2005) and Ahmedabad (August 2006) have been simulated using the WRF model (Deb et al 2008, 2010).

Six-hourly GDAS analyses from NCEP have been used for the preparation of initial and boundary conditions. The model uses various terrestrial datasets for terrain, land-use, soil type, soil temperature, vegetation fraction, snow, monthly albedo, etc., from WRF user's website (http://www.mmm.ucar.edu/wrf/users). In addition, Kalpana AMV (satellite winds), ISRO AWS and radiosonde data are assimilated to improve the model initial conditions taken from NCEP GFS.

The operational WRF model has been run for the period July 10 to September 25, 2009 and a number of $12 \mathrm{~h}, 24 \mathrm{~h}$ and $48 \mathrm{~h}$ forecasts have been produced from these analyses. These have been used in this study.

\subsection{Satellite data}

Operational geostationary satellite INSAT/ Kalpana provides high resolution (a few kilometers) and frequent ( $1 \mathrm{~h}$ or less) observations in the visible, infrared and water vapour bands. The high spatial resolution of the INSAT image makes it necessary to perform some averaging when comparing to model data.

The validation of the cloudiness forecast by models is difficult because of problems inherent in the retrieval of an 'observed' cloudiness from satellite observations of radiances (Slingo 1987). Model cloudiness is characterized by cloud parameters such as fractional cover, cloud top temperature, and cloud emissivity (Morcrette 1990). These can be either diagnosed or prognosed via a cloud generation scheme. In the diagnostic approach, cloudiness is predicted through a statistical relationship from model variables (e.g., relative humidity).

The INSAT cloud observation is generated using VHRR thermal infrared channel $(10.5-12.5 \mu \mathrm{m})$ data at spatial resolution of $8 \mathrm{~km}$. Clouds are generally characterized by higher reflectance and lower temperature than the underlying earth surface. Simple VIS/IR threshold approaches offer considerable skill in cloud detection; however, many surface conditions reduce cloud surface contrast in certain spectral regions (e.g., bright clouds over snow and ice).

\subsubsection{INSAT cloud mask algorithm}

The basis of the methodology is, first to generate a cloud composite of the maximum brightness temperature in thermal channels to get rough idea about the surface temperature in the clear sky condition at a particular time. Here the assumption is that any pixel in the image will not be covered by cloud continuously at a particular time for several days $(\approx 20)$ and the maximum brightness temperature (BTmax) will represent the clear sky background temperature of that location. This will be reference background temperature on which the threshold for a particular location will be determined to discriminate cloud. On successive days this reference will change according to that day's image. BTmax = Max (BT11 of each time of previous several (20) days).

\subsubsection{BT threshold test}

When the brightness temperature in the $11 \mu \mathrm{m}$ (BT11) channel is less by some threshold value than the maximum BT at that location, we assume the pixel to fail the clear-sky condition, because the change in $\mathrm{BT}$ will not be more than these due to change in other atmospheric condition. This test gives a first set of cloudy pixels in the image. The thresholds are given below:

If $($ BTMax - BT11) $>12 \mathrm{~K}$,

then cloud flag $=1$ (cloudy pixel) over land

If $($ BTMax - BT11) $>6 \mathrm{~K}$,

then cloud flag $=1$ (cloudy pixel) over ocean

If $\mathrm{ABS}(\mathrm{BTMax}-\mathrm{BT} 11)<2 \mathrm{~K}$,

then cloud flag $=0$ (clear sky pixel). 
Whenever BT11 is more than BTmax, BTmax is replaced with BT11 at every time - BTmax = BT11. This step is done over both land and ocean and is expected to take care of sliding composite and the seasonal changes in surface temperature at a particular location.

For the rest of the pixels cloud flag $=9$. These ambiguous pixels will be subjected to further tests to screen cloudy/clear pixels.

\subsubsection{Solar zenith angle calculation}

Solar zenith angle $(\theta)$ is calculated to determine the day/night condition of the pixel. It is given by:

$$
\begin{aligned}
\theta(\text { in radian })= & \frac{\Pi}{2}-\operatorname{Sin}^{-1}((\operatorname{Sin}(\delta) \operatorname{Sin}(\Phi)) \\
& +\operatorname{Cos}(\delta) \operatorname{Cos}(\Phi) \operatorname{Cos}(H))
\end{aligned}
$$

where $\Phi$ is the latitude, $\delta$ is the solar declination angle and $H$ is the Sun hour angle at a particular time in a calendar day.

If the solar zenith angle $>86.5$,

then pixel is considered to be falling in night time.

Else, Pixel is in day time.

Future INSAT-3D carrying a sounder will have radiance measurements at $3.9 \mu \mathrm{m}$, along with window measurements $(11 \mu \mathrm{m})$. The difference (BT11 - BT3.9) is a good measure to detect the presence (absence) of clouds during day/night time.

A few more tests like night ocean spatial variability test, spatial uniformity test, adjacent pixel test and temporal uniformity test, etc., are also carried out to further decide the cloudy/clear pixels having a cloud flag $=9$ (unambiguous pixels).

Thus the INSAT cloud mask algorithm classifies the image in to two classes: cloudy and clear. This two-class classification is required for a simple direct comparison with WRF Model fields that have also been similarly classified as grids into two classes.

\subsection{Verification strategy}

Verification is the assessment and quantification of the relationship between a matched set of forecasts and observations. Forecast verification serves many important purposes. These purposes include assessing the state-of-the-art forecasting and recent trends in forecast quality, improving forecasting procedures and ultimately the forecast themselves, and providing users with information needed to make effective use of the forecasts.
Table 2. Contingency table.

\begin{tabular}{lccc}
\hline & \multicolumn{2}{c}{ Observed } & \\
\cline { 2 - 3 } Forecast & Yes & No & Total \\
\hline Yes & Cloud hit (A) & False alarms (B) & $\begin{array}{c}\text { Forecast } \\
\text { Yes }\end{array}$ \\
No & Cloud miss (C) & $\begin{array}{c}\text { Correct negative } \\
\text { (D)-clear sky hit }\end{array}$ & $\begin{array}{c}\text { Forecast } \\
\text { No }\end{array}$ \\
Total & Observed Yes & Observed No & Total \\
\hline
\end{tabular}

Murphy and Winkler (1987) describe in detail a general framework for forecast verification based on the joint distribution of forecasts and observations. Along with the advances in NWP - forecasts has grown a body of techniques for monitoring the skill of those forecasts. It may be noted that no single 'score' is adequate; hence there is a need for several different measures of model performance.

To assess model performance quantitatively, a statistical analysis analogous to Mace et al (1998) has been performed. This involves categorical forecasts of a dichotomous event such as rain/no rain or cloudy/no cloudy (clear). We start with a contingency table (table 2) that shows the frequency of 'yes' and 'no' forecasts and occurrences. The four combinations of forecasts (yes or no) and observations (yes or no), called the joint distribution, are:

- hit: event forecast to occur, and did occur (A),

- false alarm: event forecast to occur, but did not occur (B),

- miss: event forecast not to occur, but did occur (C),

- correct negative: event forecast not to occur, and did not occur (D).

The total number of observed and forecast occurrences and non-occurrences are given on the lower and right sides of the contingency table.

The contingency table (table 2) is a useful way to see what types of errors are being made. A perfect forecast system would produce only hits and correct negatives, and no misses or false alarms. A large variety of categorical statistics are computed from these elements in the contingency table to describe particular aspects of forecast performance.

The first step in the WRF Model - INSAT cloud comparison process is to identify the INSAT pixels associated with (lying closest to) each WRF model grid point. These pixels are considered as lying within the corresponding WRF grid cell. If one of the INSAT pixel in this cell is cloudy, the grid is classified as cloudy and if all the INSAT pixels in the cell are clear, then the grid is classified as clear.

The statistical definitions for hit rate (HR), threat score (TS), probability of detection (POD), 
and false alarm rate (FAR) (from Wilks 1995) follow as:

$$
\begin{aligned}
& \text { Hit rate, } \mathrm{HR}=\frac{(\mathrm{A}+\mathrm{D})}{(\mathrm{A}+\mathrm{B}+\mathrm{C}+\mathrm{D})}, \\
& \text { Threat score, } \mathrm{TS}=\frac{\mathrm{A}}{(\mathrm{A}+\mathrm{B}+\mathrm{C})}, \\
& \text { Probability of detection, } \mathrm{POD}=\frac{\mathrm{A}}{(\mathrm{A}+\mathrm{C})}, \\
& \text { False alarm rate, FAR }=\frac{\mathrm{B}}{(\mathrm{A}+\mathrm{B})} .
\end{aligned}
$$

HR is the fraction of correctly forecasted (cloudy or clear sky) grid boxes, while TS excludes the clear sky component to focus only on clouds. The ratio of cloud hits to the total number of observed clouds is given by POD, and FAR offers a metric for how often the model's cloud forecast was wrong. A perfect forecast would thus entail $\mathrm{HR}=\mathrm{TS}=$ $\mathrm{POD}=1.0$ and $\mathrm{FAR}=0.0$ (i.e., no misses or false alarms).

Mohapatra et al (2009) have employed a similar verification strategy by using the contingency table to verify the heavy rainfall warning over east UP, west UP and Bihar during July-August issued by India Meteorological Department over the study period which included recent five years (20012005) and another epoch of five years in early 1970s.

\section{Preliminary results and discussion}

Here, we present the statistical analysis of cloud verification using WRF model cloud observations and INSAT IR Tb data for the period July 10 September 25, 2009.

Before we go to the quantitative analysis of the verification, we present the cloudiness as observed by WRF model and INSAT cloud mask (figure 1) for August 10, 2009. Qualitatively, the cloudiness as observed by WRF model and the cloud mask obtained by processing INSAT IR Imagery data match very well, except for a cloud band in the southern Arabian Sea and over south Gujarat. In general, it has been seen that during active conditions, the cloudiness in the model forecast varied between 60 and $70 \%$ and during the break conditions the corresponding number is 30 and $35 \%$. Inspite of various problems related to convective parameterization schemes employed in the model and nature of cloud generation in the model, it is very encouraging to note the good match between the cloudiness observations.

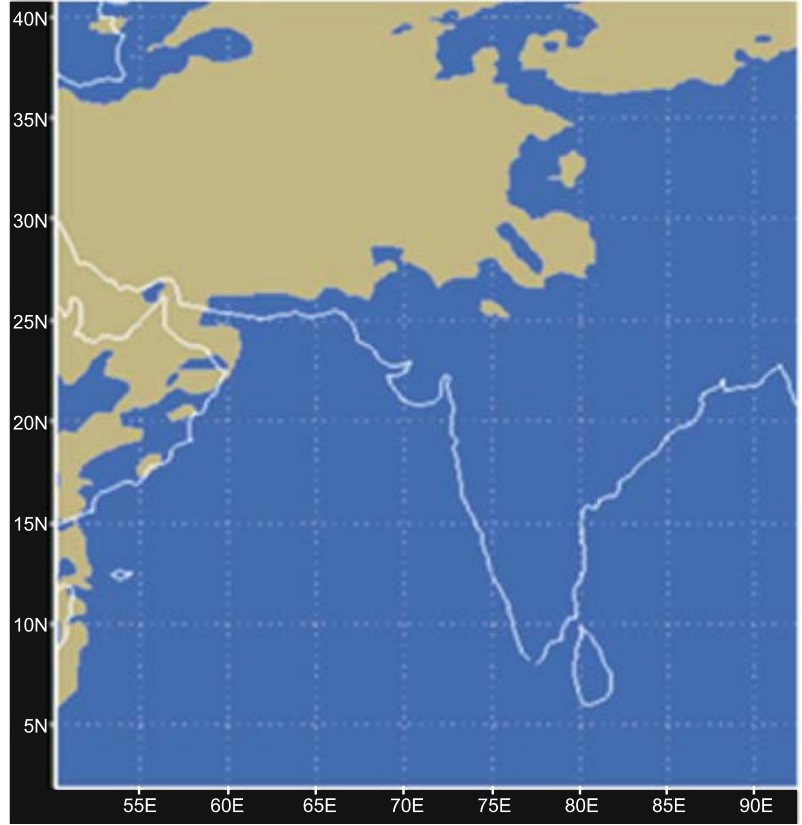

(a)

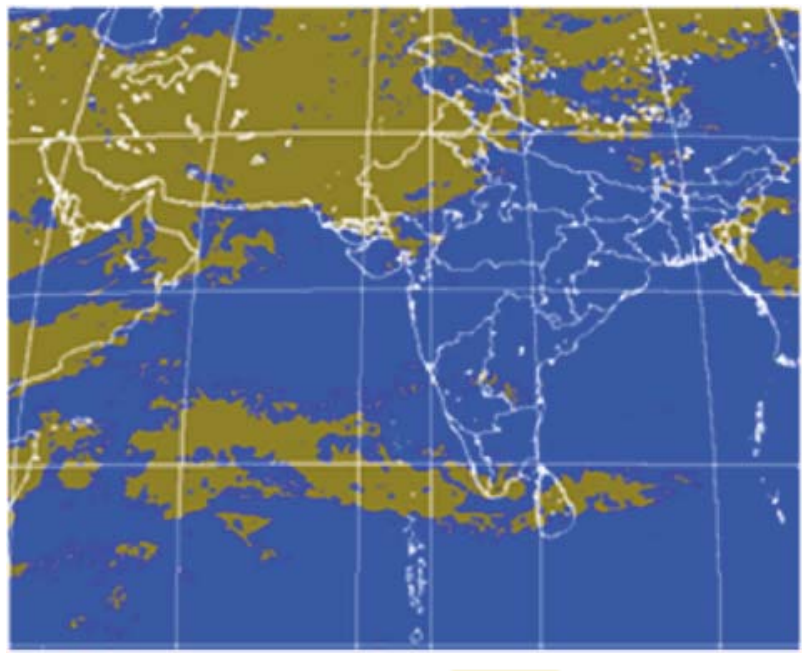

(b) Cloudy

Clear

Figure 1. (a) WRF model cloud forecast for 9 August 2009 (00GMT), (b) INSAT cloud mask product for 10 August 2009 (00GMT).

Table 3. Performance statistics for All India - 0.5 deg (July-September 2009). (See text for explanation of statistical fields.)

\begin{tabular}{lrlrlr}
\hline \multicolumn{2}{l}{ 12 h forecast } & \multicolumn{2}{c}{$24 \mathrm{~h}$ forecast } & \multicolumn{2}{c}{$48 \mathrm{~h}$ forecast } \\
\hline A & 183479 & A & 200365 & A & 192828 \\
B & 63916 & B & 44211 & B & 43762 \\
C & 7678 & C & 5346 & C & 5502 \\
D & 43692 & D & 71102 & D & 75095 \\
HR & 0.760367 & HR & 0.845628 & HR & 0.844685 \\
TS & 0.71932 & TS & 0.80171 & TS & 0.796507 \\
POD & 0.959834 & POD & 0.974012 & POD & 0.972258 \\
FAR & 0.258356 & FAR & 0.180766 & FAR & 0.18497 \\
\hline
\end{tabular}




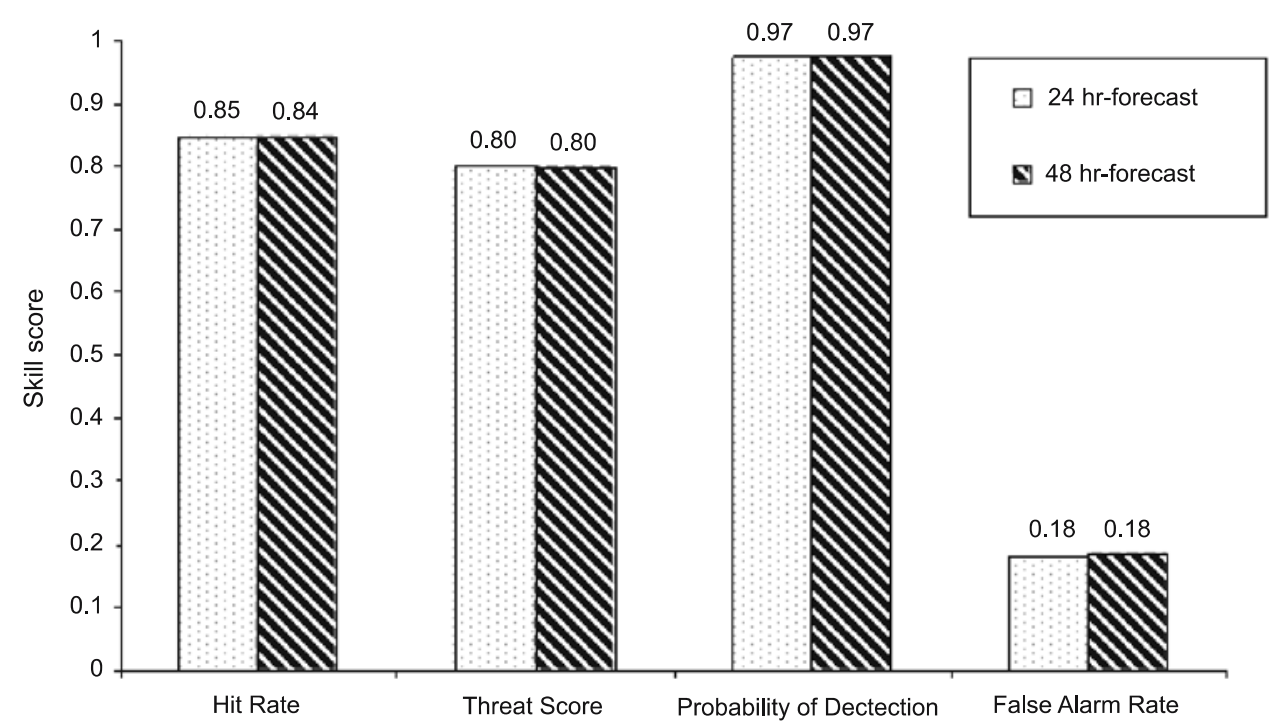

Figure 2. WRF model skill score for cloud comparison.

Using the model fields for the study period, $12 \mathrm{~h}, 24 \mathrm{~h}$ and $48 \mathrm{~h}$ forecasts have been generated at domain 1 (All India, $45 \mathrm{~km}$ ) at $0.5 \mathrm{deg}$ resolution, table 3 provides the performance statistics for the study period. The $12 \mathrm{~h}, 24 \mathrm{~h}$ and $48 \mathrm{~h}$ statistics show the WRF skills. The hit rate (HR)\% correct is around $84 \%$, while the FAR (missing rate) is $18 \%$ for $24 \mathrm{~h}$ and $48 \mathrm{~h}$ forecasts. The $24 \mathrm{~h}$ and $48 \mathrm{~h}$ forecast skill scores are also shown in the form of a bar chart (figure 2).

The total number of occurrences that INSAT and WRF matched as cloudy or clear was $84 \%$. INSAT and WRF disagreed on the remaining 16\% of the occurrences (table 4). The high TS and POD skill scores and low FAR score on the season scale does show the high utility of WRF model predicted cloudiness observations for variety of applications. It is also seen that there were more WRF only predicted clouds than INSAT only clouds, indicating a high bias towards overprediction of cloudiness by WRF.

We have also performed the analysis by segregating the active and break periods during the study period. It is seen that the skill scores do not show appreciable changes from the active to break situations. The HR and FAR scores (not shown) are similar to the entire study period as discussed above.

In order to study the sensitivity of the WRF model to domain size, we have used the $24 \mathrm{~h}$ forecast fields at domain $3(5 \mathrm{~km})$ of the model to assess the ability of the model to correctly predict the cloud presence. For this purpose, we have used 190 station data to extract cloud information from INSAT data. The $5 \mathrm{~km}$ domain 3 data is converted to respective station point by finding the nearest point of the model corresponding to the
Table 4. The number of occurrences and percentage from total for each classification (all India, $48 \mathrm{~h}$ forecast).

\begin{tabular}{lcr}
\hline Output & $\begin{array}{c}\text { No. of } \\
\text { occurrences }\end{array}$ & $\begin{array}{r}\text { Percent } \\
\text { of total }\end{array}$ \\
\hline A - Cloud INSAT and WRF & 192828 & $61 \%$ \\
B - Cloud WRF only & 43762 & $14 \%$ \\
C - Cloud INSAT only & 5502 & $2 \%$ \\
D - Clear INSAT and WRF & 75095 & $23 \%$ \\
\hline
\end{tabular}

Table 5. Performance statistics: Station data (5 $\mathrm{km}$ resolution), $24 \mathrm{~h}$ forecast.

\begin{tabular}{lr}
\hline A & 4998 \\
B & 4150 \\
C & 189 \\
D & 1038 \\
HR & 0.58 \\
TS & 0.54 \\
POD & 0.96 \\
FAR & 0.45 \\
\hline
\end{tabular}

station latitude-longitude. Since the INSAT cloud mask data is at $8 \mathrm{~km}$ resolution, to collocate the nearest lat.-long. for the station to the INSAT pixel, nearest point falling in the $7 \mathrm{~km}$ radius is taken as the collocated point.

Table 5 provides the performance statistics computed for 190 stations during the period July 10September 25, 2009. In this case $58 \%$ of the time INSAT and WRF matched as either cloudy or clear and on the remaining $42 \%$ of the time INSAT and WRF disagreed. While HR is seen to around $58 \%$, the FAR is $45 \%$. In comparison 
to table 3 , it is concluded that the model is adequate to simulate the cloudiness observations at coarser resolutions than high resolutions. Miller et al (1999) have performed similar skill analysis for the assessment of the ECMWF prognostic cloud scheme using data from Lidar In-space Technology Experiment (LITE). It is well-known that in case of variables like clouds, precipitation and visibility, etc., the errors at a point are quite large as compared to an areal estimate.

\section{Conclusion}

The purpose of this study was to explore a way to examine the difference between the INSAT cloud mask and the WRF cloudiness prediction. The study covered approximately 90 days period during the southwest monsoon 2009. The total number of occurrences that INSAT and WRF matched as cloudy or clear was $84 \%$. INSAT and WRF disagreed on the remaining $16 \%$ of the occurrences. It is very difficult to get a model to predict the observed cloud presence (Otkin and Greenwald 2008). Considering the various uncertainties in the cloud processes in the model which could result in ambiguous forecast values of cloudiness, the high hit rate (HR) and the low false alarm rate (FAR) indicate the utility of WRF predicted cloudiness observations for various applications. These verifications would form an important input for the modelers in addressing issues related to cloud parameterization schemes employed, as well as in applications related to satellite missions for the acquisition of cloud free data.

\section{Acknowledgements}

The authors wish to thank Dr R R Navalgund, Director, SAC and Shri A S Kirankumar, Associate Director, SAC for their keen interest and encouragement.

\section{References}

Chen F and Dudhia J 2001 Coupling an advanced land surface/hydrology model with Penn State/NCAR MM5 modeling system. Part I: Model description and implementation; Mon. Wea. Rev. 129 569-585.

Deb S K, Srivastava T P and Kishtawal C M 2008 The WRF model performance for the simulation of heavy precipitation events over Ahmedabad during August 2006; J. Earth Syst. Sci. 117 589-602.
Deb S K, Kishtawal C M, Bongirwar V S and Pal P K 2010 The simulation of heavy rainfall episode over Mumbai: Impact of horizontal resolutions and cumulus parameterization schemes; Nat. Hazards (Springer) 52 117-142.

Dudhia J, Hong S Y and Lim K S 2008 A new method for representing mixed phase particle fall speeds in bulk microphysics parameterizations; J. Met. Soc. Japan 86A $33-44$.

Hong S Y, Dudhia J and Chen S H 2004 A revised approach to ice microphysical processes for the bulk parameterization of clouds and precipitation; Mon. Wea. Rev. 132 103-120.

Hong S Y, Noh Y and Dudhia J 2006 A new vertical diffusion package with an explicit treatment processes; Mon. Wea. Rev. $1342318-2341$.

Kain J S and Fritsch J M 1990 A one dimensional entraining/detraining plume model and its application in convective parameterization; J. Atmos. Sci. 47 $2784-2802$.

Kain J S and Fritsch J M 1993 Convective parameterizations for mesoscale models: The Kain-Fritsch scheme; In: The representation of cumulus convection in numerical models (eds) Emanuel K A and Raymond D J, Amer. Meteor. Soc. $246 \mathrm{pp}$.

Kain J S 2004 The Kain-Fritsch convective parameterization: An update; J. Appl. Meteor. 43 170-181.

Lin Y L, Farley R D and Orville H D 1983 Bulk parameterization of the snow field in a cloud model; J. Clim. Appl. Meteor. 22 1065-1092.

Mace G G, Jakob C and Moran K P 1998 Validation of hydrometeor occurrence predicted by the ECMWF model using millimeter wave radar data; Geophys. Res. Lett. 25(10) 1645-1648.

Miller S D, Stephans G L, Beljaars A C M 1999 A validation survey of the ECMWF prognostic cloud scheme using LITE; Geophys. Res. Lett. 26(10) 1417-1420.

Mlawer E J, Taubman S J, Brown P D, Iacono M J and Clough S A 1997 Radiative transfer for imhomogeneous atmosphere: RRTM, a validated correlated $\mathrm{k}$ model for the longwave; J. Geophys. Res. 102(D14) $16,663-16,682$.

Mohapatra M, Hatwar H R and Kalsi S R 2009 Verification of heavy rainfall warning over Bihar and Uttar Pradesh; Mausam 60 175-184.

Molders N, Laube M and Raschke E 1995 Evaluation of model generated cloud cover by means of satellite data; Atmos. Res. 39 91-111.

Morcrette J J 1990 Evaluation of model-generated cloudiness: Satellite-observed and model-generated diurnal variability of brightness temperature; Mon. Wea. Rev. 119 1205-1224.

Murphy A H and Winkler R L 1987 A general framework for forecast verification; Mon. Wea. Rev. 115 $1330-1338$.

Otkin J A and Greenwald T J 2008 Comparison of WRF model-simulated and MODIS-derived cloud data; Mon. Wea. Rev. 136 1957-1970.

Slingo J M 1987 The development and verification of a cloud prediction scheme for the ECMWF model; Q. J. R. Meteorol. Soc. 113 899-927.

Wicker L J and Skamarock W C 2002 Time splitting methods for elastic models using forward time schemes; Mon. Wea. Rev. 130 2088-2097.

Wilks D S 1995 Statistical methods in the atmospheric sciences: An introduction; Academic Press, 467 pp. 